\title{
Analysis of Piperine in Black Pepper by High Performance Liquid Chromatography
}

\author{
Suraj Shrestha*1, Nibedita Chaudhary ${ }^{1}$, Rajkumari Sah ${ }^{1}$, Neera Malakar ${ }^{1}$ \\ ${ }^{I}$ National Food \& Feed Reference Laboratory, Department of Food Technology and Quality Control, Kathmandu, Nepal \\ *Corresponding E-mail: sthasuraz4@gmail.com
}

(Received: March 15, 2020; Revised: May 30, 2020 \& Accepted: June 12, 2020)

\begin{abstract}
Piperine is the most important alkaloid present in the black pepper. A high performance liquid chromatography (HPLC) method proposed by International Organization for Standardization (ISO) was optimized and validated for quantitative determination of piperine in black pepper. The method was successfully validated for linearity, range, accuracy, precision, limit of detection, limit of quantitation, and measurement uncertainty. The validated method was used for the analysis of nine black pepper samples collected from the local supermarket of Kathmandu. The piperine content of the samples collected from various areas of Kathmandu, Nepal were found in the range of $2.33 \%$ to $3.34 \%$ with an average of $2.75 \%$ and a standard deviation of $0.31 \%$. This simple, precise, and accurate method can be used for routine analysis of piperine content in black pepper for quality control purposes.
\end{abstract}

Keywords: Black pepper, piperine, HPLC, method validation

\section{Introduction}

Black pepper (Piper nigrum L.) is used as spices in many countries. It has been ranked at a supreme position among the spices due to its characteristic pungency and flavor [1]. It is also known as the king of spices based on the volume of international trade [2]. The characteristic pungent smell of black pepper is due to the presence of alkaloid, piperine. It is the most abundant and most important alkaloid present in black pepper. In 1821, Oerstedt H Schweigers isolated piperine from ground black pepper and also found that the pungency of black pepper is due to piperine [3]. Black pepper was used traditionally not only for seasoning of foods but for other medicinal purposes also. It has been traditionally used for cholera, dyspepsia, gastric ailments, and diarrhea [4]. Similarly, it exhibits various physiological properties including carminative, diaphoretic, diuretic, lipolytic, etc. [5]. Nowadays, more research is focused on the medicinal properties of piperine. It has beenshown antimutagenic effects in reducing the DNA damages caused by carcinogens in somatic and germ cells [6], play an important role against benzo(a)pyrene induced lung carcinogenesis by protecting the glycoprotein levels in serum and tissues in Swiss albino mice [7]. It is effective in prostate cancer [8]. Similarly, it has also been shown to protect against high-fat induced oxidative stress to cells [9]. Although piperine has diverse therapeutic properties, its use as a medicine is limited due to poor solubility in water $(40 \mathrm{mg} / \mathrm{L}$ at 18 $\left.{ }^{\circ} \mathrm{C}\right)[10]$. Thus recent studies focus on the formulation of more water soluble nano particle based piperine for the treatment of various diseases [11]. The picture of black pepper and its major constituent piperine is as shown in Figure 1.

The quality of black pepper is correlated with the piperine content in it. The piperine content varies from pepper to pepper and amount can be influenced by many factors such as climate, growing conditions, and its place of origin. The amount of piperine varies significantly from $1.6 \%$ to $9 \%$ in black pepper $[12,13]$.

The Codex Alimentarius has established the minimum level of piperine in black pepper in CXS 326-2017, where the black peppers are classified into grade I, grade II, and grade III. The minimum piperine content for I, II and III grade black peppers are 3.5\%, 3.0\%, 

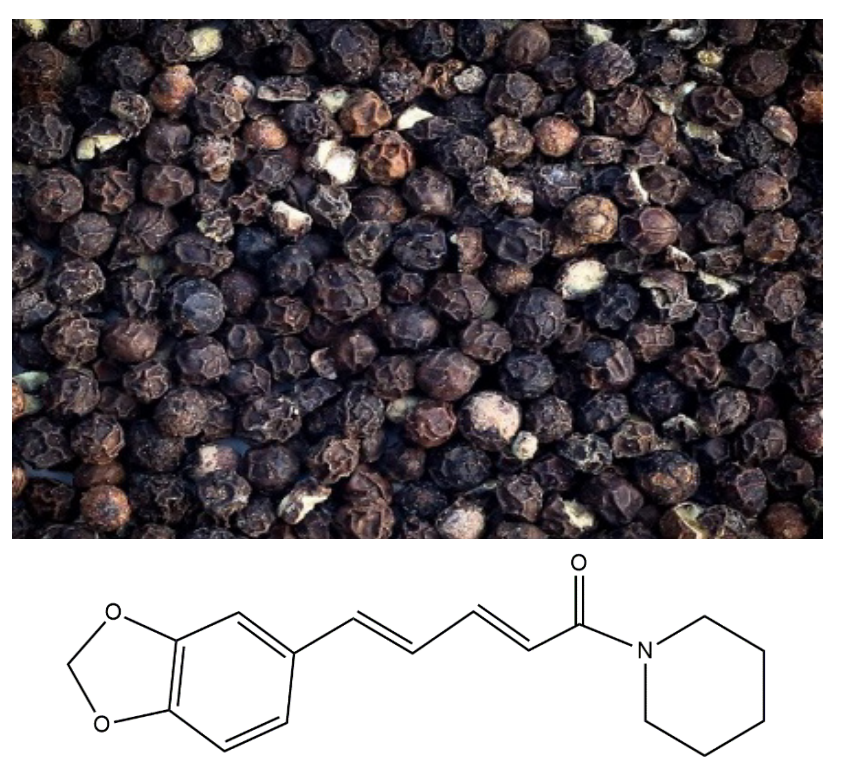

Figure 1: Black pepper and structure of piperine

and $2.0 \%$ on dry weight basis respectively [14]. Food Safety and Standard Authority of India (FSSAI) does not classify black pepper into different classes but the piperine content for all types of black pepper samples should not be less than $4.0 \%$ on dry weight basis [15]. However, in Nepal, the standard for piperine content in black pepper has not been set and the method for analysis of piperine in black pepper has not been established yet.

There are various analytical methods available for analysis of piperine in black pepper such as HPTLC [16,17], UV-Vis Spectroscopy [18,19] GC-FID [20] and HPLC [21,22]. In this study, a simple precise and accurate HPLC method proposed by ISO was used for analysis [23] after validation. Critical method parameters such as linearity, range, limit of detection (LOD), limit of quantitation (LOQ), accuracy, precision and measurement uncertainty were evaluated to check whether the method is fit for routine analysis of piperine by a quality control laboratory or not.

The objectives of this study were to establish and validate the HPLC method for routine analysis of piperine in black pepper as well as to find the baseline status of piperine content in black peppers available in Nepali market. This baseline data would be helpful for setting the standard of piperine in black pepper by the government of Nepal.

\section{Materials and Methods}

\section{Chemicals and reagents}

All chemical reagents used for analysis were analytical grade. The chemicals include ethanol, $96 \%$ $(\mathrm{V} / \mathrm{V})$, acetonitrile (HPLC grade) and acetic acid (1\% acetic acid solution in water). HPLC grade water was prepared from Milli Q system. Traceable standard for piperine was purchased from Sigma Aldrich, Germany.

\section{Instrumentation and chromatographic conditions}

Identification and quantification of thepiperine was performed with Shimadzu prominence HPLC system equipped with CBM 20 alite controller, DGU-20 A5 prominence online degasser, LC-20AD binary pumps, SIL-20A prominence auto sampler, CTO-20 prominence column oven and SPD-20A prominence UV-Vis detector (Shimadzu Co., Kyoto, Japan). The chromatographic separation was performed in the reversed phase $\mathrm{C} 18$ analytical column of dimension $4.6^{*} 150 \mathrm{~mm}$ and $5 \mu \mathrm{m}$ particle size. Isocratic elution containing $48 \%$ of acetonitrile and $52 \%$ of $1 \%$ acetic acid in water was used as mobile phase for the analysis. The constant flow rate of $1 \mathrm{~mL} / \mathrm{min}$ was maintained throughout the run. Column was kept in the column oven maintained at a constant temperature of $40^{\circ} \mathrm{C} .10 \mu \mathrm{L}$ of both standards and samples were injected into the system and piperine peak was monitored at $343 \mathrm{~nm}$. The run time was set to $25 \mathrm{~min}$, which may vary from column to column as well as chromatographic conditions.

\section{Standard solution preparation}

Stock solution of $1000 \mathrm{ppm}(\mathrm{mg} / \mathrm{L})$ of piperine was prepared by dissolving $10 \mathrm{mg}$ standard in to $10 \mathrm{~mL}$ class-A volumetric flask with ethanol. The stock solution was kept in a refrigerator. From this stock standard solution, five calibration standard solutions from $1 \mathrm{ppm}$ to $200 \mathrm{ppm}$ were prepared by appropriate dilution with diluent solvent (a mixture of 52 parts volumes of $1 \%$ acetic acid in water solution and 48 parts volumes of acetonitrile). Due to the light sensitivity of piperine, all the standard solutions were prepared in amber colored glasswares.

\section{Sample collection and preparation}

Nine samples of black peppers were collected from different supermarkets located at Anamnagar, 
Kamalpokhari, Pulchowk, Asan area of Kathmandu, Nepal. Collected samples were finely ground in a mixture grinder and the powder was passed through $500 \mu \mathrm{m}$ sieve. $0.5 \mathrm{~g}$ to $1 \mathrm{~g}$ powder sample was weighed in a butter paper and transferred to a $250 \mathrm{~mL}$ round bottom flask fitted with a reflux condenser. $50 \mathrm{~mL}$ ethanol was added, swirl and mixture was refluxed for 3 hours then it was cooled to room temperature. The solution was filtered and collected in a $100 \mathrm{~mL}$ volumetric flask. Round bottom flask and filter paper were rinsed with successive portions of ethanol into the same volumetric flask. Volume was made up to the mark with more ethanol. The flask was shaken thoroughly and $4 \mathrm{~mL}$ solution was transferred into a $10 \mathrm{~mL}$ volumetric flask and volume was made up to the mark with the diluent solvent. The flask was shaken thoroughly and an appropriate amount of liquid was transferred via disposable syringe into an HPLC vial after passing through a $0.45 \mu \mathrm{m}$ syringe membrane filter. The vial was kept into the auto sampler of HPLC for analysis.

\section{Method validation}

This study was based on the standard ISO method with some minor modifications. So as per the requirement of ISO/IEC 17025:2017 [24], method validation was performed before routine analysis to ensure that it can achieve the required performance. During method validation various validation parameters such as linearity, range, accuracy, precision, limit of detection (LOD), limit of quantitation (LOQ) and measurement uncertainty (MU) were calculated.

\section{Results and Discussion}

\section{Method validation}

Following method validation parameters were investigated in this study.

\section{Linearity and range}

The calibration curve was plotted between peak areas of different concentrations versus their nominal concentrations, which is shown in figure 2. Linearity of method was tested by injecting 5 different concentrations in duplicate, ranging from $1 \mathrm{ppm}$ to $200 \mathrm{ppm}$. The correlation coefficient $\left(\mathrm{r}^{2}\right)$ was more than 0.999. Retention times (RT) and areas of all peaks of standards are shown in table 1.

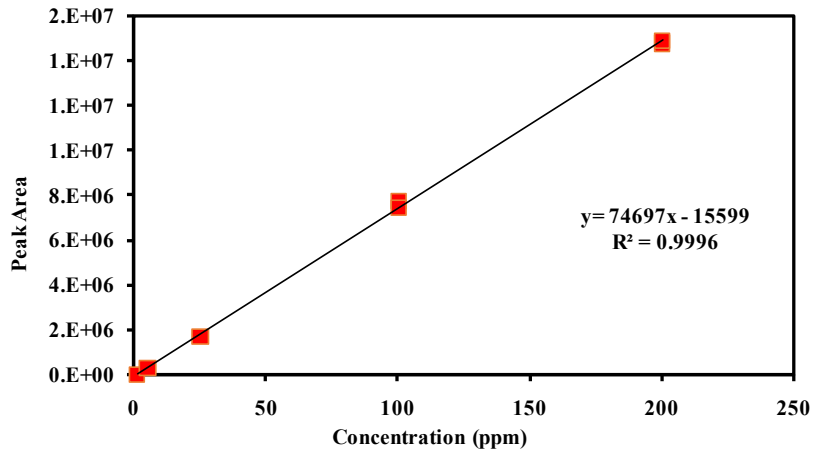

Figure 2: Calibration curve of piperine

The percentage relative standard deviation (\% RSD) was found to be $0.126 \%$ only, which indicates that there is no significant drift of retention time of piperine.

The method range was from $0.10 \%$ (corresponding to $2 \mathrm{ppm}$ vial concentration, dilution around 500 times) to $10 \%$ (corresponding to $200 \mathrm{ppm}$ vial concentration, dilution around 500 times).

Table1: Retention time (RT) and area of standard solution

\begin{tabular}{|c|c|c|c|}
\hline Name & $\begin{array}{l}\text { Standard } \\
\text { conc. }(\text { ppm })\end{array}$ & $\begin{array}{l}\text { Retention } \\
\text { time (min) }\end{array}$ & Area \\
\hline 1 ppm std 1 & 1 & 11.24 & 67,235 \\
\hline 1 ppm std 2 & 1 & 11.258 & 67,338 \\
\hline 5 ppm std 1 & 5 & 11.247 & 340,569 \\
\hline 5 ppm std 2 & 5 & 11.265 & 340,411 \\
\hline 25 ppm std 1 & 25 & 11.239 & $1,765,767$ \\
\hline 25 ppm std 2 & 25 & 11.269 & $1,764,899$ \\
\hline 100 ppm std 1 & 100 & 11.241 & $7,762,476$ \\
\hline 100 ppm std 2 & 100 & 11.264 & $7,483,803$ \\
\hline 200 ppm std 1 & 200 & 11.258 & $14,806,722$ \\
\hline 200 ppm std 2 & 200 & 11.281 & $14,894,411$ \\
\hline \multicolumn{2}{|l|}{ Average } & \multicolumn{2}{|l|}{11.2562} \\
\hline \multicolumn{2}{|c|}{ Standard deviation } & \multicolumn{2}{|l|}{0.014133} \\
\hline \multicolumn{2}{|c|}{$\begin{array}{l}\text { \% Relative standard deviation } \\
\text { (\%RSD) }\end{array}$} & 0.126 & \\
\hline
\end{tabular}

\section{Precision}

Precision was evaluated by repeatability. Six replicates of the same black pepper samples were prepared and analyzed separately. The obtained values are summarized in table 2. The average piperine content and percentage relative standard deviation ( $\%$ RSD) values were determined. The average value of 
Table 2: Precision (as repeatability) of the method

\begin{tabular}{lcccccc}
\hline Name & $\begin{array}{l}\text { Wt. } \\
\text { taken (g) }\end{array}$ & $\begin{array}{l}\text { Vol. make } \\
\text { up (mL) }\end{array}$ & $\begin{array}{l}\text { Aliquot } \\
\text { extract (mL) }\end{array}$ & $\begin{array}{l}\text { Final } \\
\text { vol. (mL) }\end{array}$ & $\begin{array}{l}\text { Conc. from } \\
\text { HPLC (ppm) }\end{array}$ & $\begin{array}{l}\text { Piperine } \\
\text { conc. (\%) }\end{array}$ \\
\hline Repeatability-1 & 0.5190 & 100 & 4 & 10 & 54.615 & $\mathbf{2 . 6 3}$ \\
Repeatability-2 & 0.5135 & 100 & 4 & 10 & 52.839 & $\mathbf{2 . 5 7}$ \\
Repeatability-3 & 0.5172 & 100 & 4 & 10 & 58.421 & $\mathbf{2 . 8 2}$ \\
Repeatability-4 & 0.5191 & 100 & 4 & 10 & 55.697 & $\mathbf{2 . 6 8}$ \\
Repeatability-5 & 0.5196 & 100 & 4 & 10 & 54.809 & $\mathbf{2 . 6 4}$ \\
Repeatability-6 & 0.5187 & 100 & 4 & 10 & 55.833 & $\mathbf{2 . 6 9}$ \\
\hline Average & \\
\hline \multicolumn{7}{l}{ Standard deviation } \\
Percentage relative standard deviation (\% RSD)
\end{tabular}

piperine in six replicates was found to be $2.67 \%$ while percentage relative standard deviation (\% RSD) was found to be $3.19 \%$, indicating good precision of the method.

\section{Accuracy}

The accuracy of the method was evaluated by recovery studies. Since piperine is an inherent constituent of peppers, a blank sample was not available. Thus, recovery check was performed by spiking a known amount of standard piperine solution in the already analyzed pepper sample. The obtained values are summarized in table 3. Triplicate spiking was performed and the average recovery was calculated. The recovery of the method was found to be $100 \%$ with percentage relative standard deviation( $\%$ RSD) of $6.7 \%$.

\section{Limit of detection (LOD) and limit of quantitation (LOQ)}

In this study, method limit of detection and method limit of quantitation were calculated instead of instrumental limit of detection and limit of quantitation for better representation of method. The sample solutions were diluted, due to the unavailability of blank samples, and were injected to estimate LOD and LOQ level. Signal to noise ratio of 3 and 10 were used for LOD and LOQ determination respectively. The method LOD was found to $0.04 \%$ while method LOQ was found to be $0.1 \%$.

\section{Measurement uncertainty (MU)}

The measurement of uncertainty was calculated as per ISO GUM modeling approach [25-27], where every steps of the method were considered and major uncertainty contributors were identified. The standard uncertainty of every contributor was calculated and summed as per the law of propagation of uncertainty to give combined standard uncertainty. The combined standard uncertainty was finally expressed as expanded uncertainty at $95 \%$ confidence level. The evaluated expanded uncertainty was $\pm 0.18 \%$ and it is expressed as $(2.67 \pm 0.18) \%$ at $95 \%$ confidence level.

Table 3: Accuracy (as recovery) of the method

\begin{tabular}{lcccc} 
Name & $\begin{array}{c}\text { Obtained conc. } \\
\text { of piperine (\%) }\end{array}$ & $\begin{array}{c}\text { Conc. of spiked } \\
\text { piperine (\%) }\end{array}$ & $\begin{array}{c}\text { Theoretical conc. of } \\
\text { piperine after spiking (\%) }\end{array}$ & \% Recovery \\
\hline Sample & 2.67 & - & - & 106 \\
Sample spiked-1 & 3.00 & 0.14 & 2.82 & 93 \\
Sample spiked-2 & 2.62 & 0.15 & 2.82 & 101 \\
Sample spiked-3 & 2.83 & 0.14 & & $\mathbf{1 0 0}$ \\
\hline Average & & $\mathbf{6 . 7}$ \\
\hline Standard deviation & & $\mathbf{6 . 7}$ \\
\hline
\end{tabular}


Table 4: Piperine content in black pepper samples

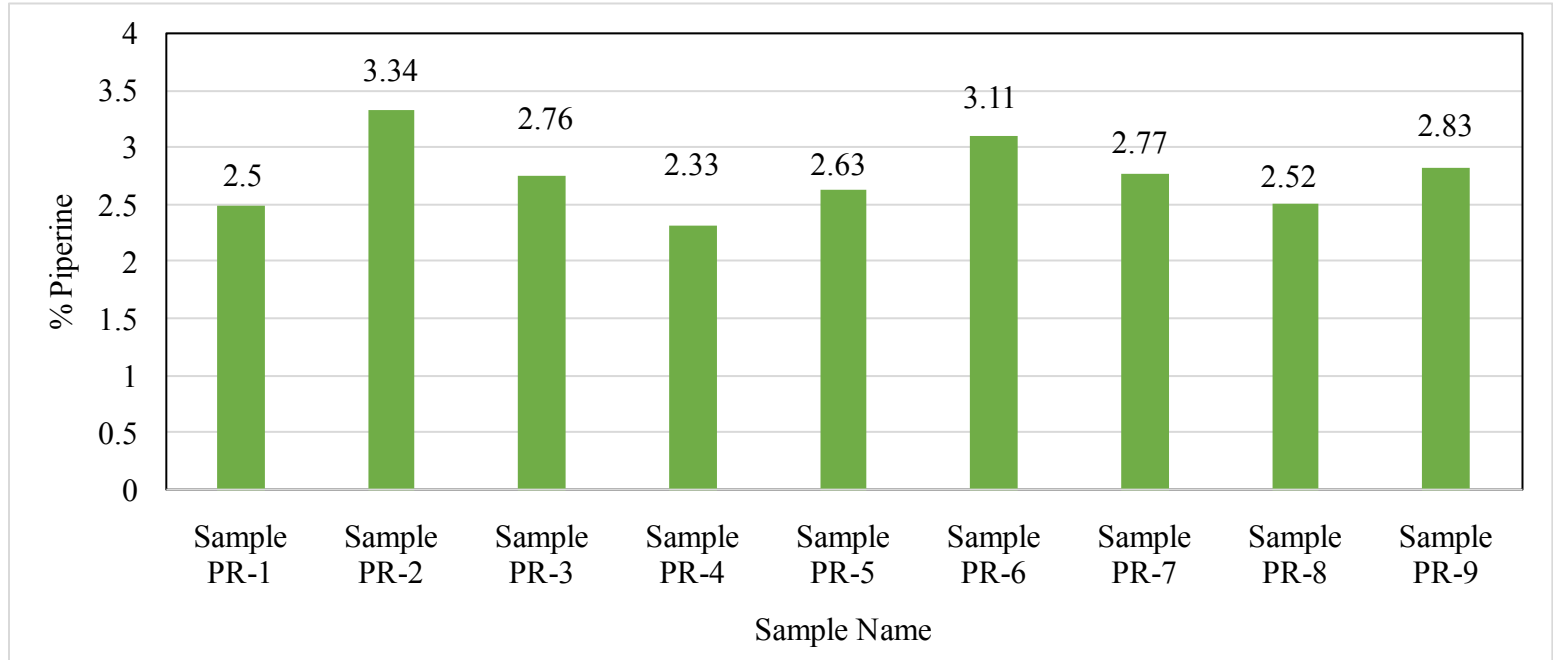

\section{Sample analysis}

After successful establishment and validation of the method, nine samples were analyzed. The amount of piperine in each sample is shown in table 4 . The piperine contents of the samples were found in the range of $2.33 \%$ to $3.34 \%$ with an average of $2.75 \%$ and standard deviation of $0.31 \%$. Chromatograms of a standard and sample were shown in figures $3 \mathrm{a}$ and $3 \mathrm{~b}$. All the method validation parameters are satisfactory to be used as a routine method for aquality control laboratory. The measurement uncertainty value helps in the statement of conformity as per the specifications of the product. The obtained values of piperine show that its content in the black pepper samples collected from different supermarkets of Kathmandu, Nepal fall in the grade II (piperine content minimum 3\%) and grade III (piperine content minimum 2\%) of black pepper as classified in Codex Alimentarius.

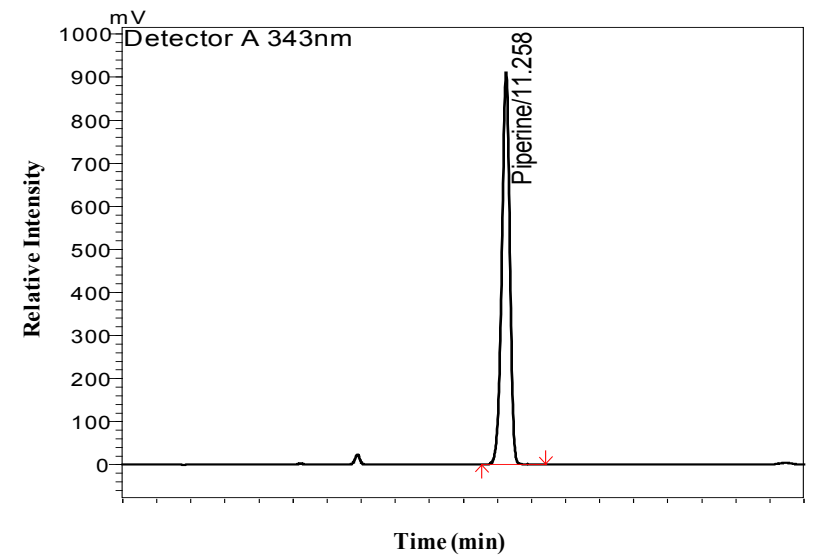

Figure 3a: Chromatogram of piperine standard (200 ppm)

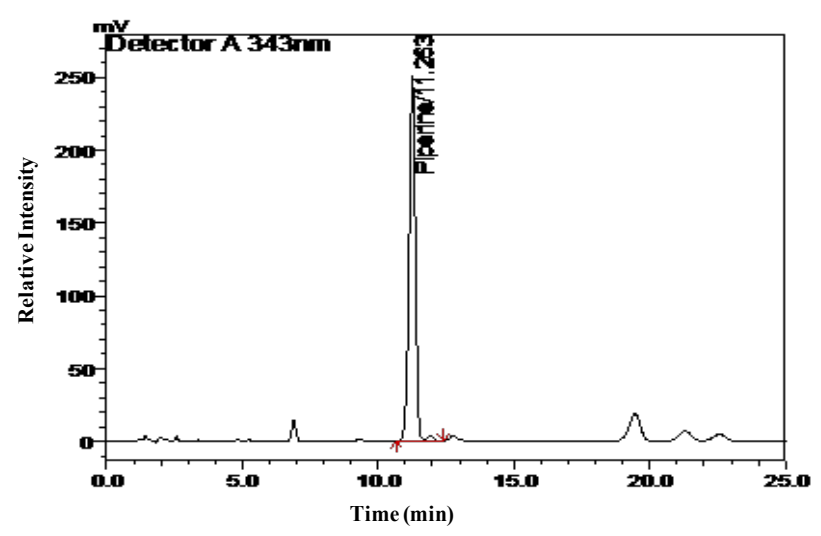

Figure 3b: Chromatogram of sample piperine

However, these values were found to be lower than the minimum level of piperine set by FSSAI (piperine content minimum $4 \%$ ). It is one of the expensive spices, its stringent quality control is desirable for the value of money paid by the customer.

In Nepal, black peppers are produced in a small amount while a large amount of it is imported from India. This validated method can be used to control the import of black pepper samples with the required minimum level of piperine. This will facilitate the import, export of black peppers. Similarly, data of piperine generated in this study can be used as baseline data for piperine content in black peppers available in the Nepali market during setting the minimum level of piperine in black pepper by the government of Nepal. Further research involving a large number of black pepper samples are necessary for the status of piperine in black pepper samples available in Nepal. 


\section{Conclusion}

A simple precise and accurate HPLC method is successfully established and validated for piperine content in black pepper. All the tested method validation parameters are satisfactory. Nine black pepper samples collected from different places of Kathmandu, Nepal were analyzed with this method successfully and this method can be used for routine analysis of black pepper for quality control purposes.

\section{Acknowledgments}

The authors would like to thank Department of Food Technology \& Quality Control, Nepal and Nepal Government for financial support to conduct this research.

\section{References}

1. L. Gorgani, M. Mohammadi, G. D. Najafpour, and M. Nikzad, Piperine-the bioactive compound of black pepper: from isolation to medicinal formulations, Comprehensive Reviews in Food Science and Food Safety, 2017, 16, 124-140. (DOI: 10.1111/1541-4337.12246).

2. K. Srinivasan, Black pepper and its pungent principle-piperine: A review of diverse physiological effects, Critical Reviews in Food Science and Nutrition, 2007, 47, 735-748. (DOI: 10.1080/10408390601062054).

3. K. Saha, H. Seal, and M. Noor, Isolation and characterization of piperine from the fruits of black pepper (Piper nigrum), Journal of the Bangladesh Agricultural University, 2014, 11, 11-16. (DOI: 10.3329/jbau.v11i1.18197).

4. U. H. Park, H. S. Jeong, E. Y. Jo, T. Park, S. K. Yoon, E. J. Kim, J. C. Jeong, and S. J. Um, Piperine, a component of black pepper, inhibits adipogenesis by antagonizing PPAR $\gamma$ activity in 3T3-L1 cells, Journal of Agricultural and Food Chemistry, 2012, 60, 3853-3860. (DOI: 10.1021/ jf204514a).

5. W. W. Epstein, D. F. Netz, and J. L. Seidel, Isolation of piperine from black pepper, Journal of Chemical Education, 1993, 70, 598-599. (DOI: 10.1021/ed070p598).

6. M. A. M. Abo-zeid, and A. A. Farghaly, The antimutagenic activity of piperine against mitomycine
$C$ induced sister chromatid exchanges and chromosomal aberrations in mice, Nature and Science, 2009, 7, 72-78.

7. K. Selvendiran, J. Prince Vijeya Singh, and D. Sakthisekaran, In vivo effect of piperine on serum and tissue glycoprotein levels in benzo(a) pyrene induced lung carcinogenesis in Swiss albino mice, Pulmonary Pharmacology and Therapeutics, 2006, 19, 107-111. (DOI: 10.1016/j. pupt.2005.04.002).

8. A. Samykutty, A.V. Shetty, G. Dakshinamoorthy, M. M. Bartik, G. L. Johnson, B. Webb, G. Zheng, A. Chen, R. Kalyanasundaram, and G. Munirathinam, Piperine, a bioactive component of pepper spice exerts therapeutic effects on androgen dependent and androgen independent prostate cancer cells, PLOS ONE, 2013, 8, 1-11. (DOI: 10.1371/journal.pone.0065889).

9. R. S. Vijayakumar, D. Surya, and N. Nalini, Antioxidant efficacy of black pepper (Piper nigrum L.) and piperine in rats with high fat diet induced oxidative stress, Redox Report, 2004, 9, 105-110. (DOI: 10.1179/135100004225004742).

10. K. Vasavirama, and M. Upender, Piperine: a valuable alkaloid from piper species, International Journal of Pharmacy and Pharmaceutical Sciences, 2014, 6, 34-38.

11. T. Ren, M. Hu, Y. Cheng, T. L. Shek, M. Xiao, N. J. Ho, C. Zhang, S. S. Y. Leung, and Z. Zuo, Piperine-loaded nanoparticles with enhanced dissolution and oral bioavailability for epilepsy control, European Journal of Pharmaceutical Sciences, 2019, 137, 104988. (DOI: 10.1016/j. ejps.2019.104988).

12. M. N. Nagar, Isolation, identification and quantitative analysis of piperine from Piper nigrum Linn of various regions of Kerala by RPHPLC method, Ajmal World Journal of Pharmacy and Pharmaceutical Sciences, 2018, 7, 10231049. (DOI: 10.20959/wjpps20186-11743).

13. V. K. Chaudhri, Isolation and evaluation of piperine from black pepper and white pepper, World Journal of Pharmacy and Pharmaceutical Sciences, 2017, 6, 1424-1430. (DOI: 10.20959/ wjpps20178-9752). 
14. Joint FAO/WHO Codex Alimentarius Commission, CXS 326-2017 Codex Alimentarius: Standard for Black, White and Green Peppers, World Health Organization: Food and Agriculture Organization of the United Nations, Italy, 2017.

15. FSSAI, Food Safety and Standards (Food Products standards and Food Additives) Regulations, 2011, Version-IX, Food Safety and Standards Authority of India, India, 2019.

16. A. A. Rajopadhye, A. S. Upadhye, and A. M. Mujumdar, HPTLC method for analysis of piperine in fruits of Piper species, Journal of Planar Chromatography-Modern TLC, 2011, 24, 57-59. (DOI: 10.1556/JPC.24.2011.1.11).

17. P. D. Hamrapurkar, K. Jadhav, and S. Zine, Quantitative estimation of piperine in Piper nigrum and Piper longum using high performance thin layer chromatography, Journal of Applied Pharmaceutical Science, 2011, 1, 117-120.

18. S. K. Chauhan, G. P. Kimothi, B. P. Singh, and S. Agarwal, A spectrophotometric method to estimate piperine in piper species, Ancient Science of Life, 1998, 18, 84-7.

19. Y. B. Murti, Y. S. Hartini, W. L. J. Hinrichs, H. W. Frijlink, and D. Setyaningsih, UV-Vis spectroscopy to enable determination of the dissolution behavior of solid dispersions containing curcumin and piperine, Journal of Young Pharmacists, 2018, 11, 26-30. (DOI: 10.5530/jyp.2019.11.6).

20. I. Noyer, B. Fayet, I. Pouliquen-Sonaglia, M. Guerere, and J. Lesgard, Quantitative analysis of pungent principles of Pepper oleoresins: comparative study of three analytical methods, Analusis, 1999, 27, 69-74. (DOI: 10.1051/ analusis:1999109).
21. M. KS, D. Shaila, I. Rajyalakshmi, and I. S. Rao, RP -HPLC method for determination of piperine from, E-Journal of Chemistry, 2005, 2, 131-135.

22. S. R. Kolhe, P. Borole, and U. Patel, Extraction and evaluation of piperine from Piper nigrum Linn, International Journal of Applied Biology and Pharmaceutical Technology, 2011, 2, 144149. www.ijabpt.com.

23. ISO, ISO 11027:1993 Pepper and pepper oleoresins-determination of piperine content -method using high-performance liquid chromatography, International Organization for Standardization, Switzerland, 1993.

24. ISO, ISO/IEC 17025:2017 General requirements for the competence of testing and calibration laboratories, International Organization for Standardization, Switzerland, 2017.

25. JCGM, JCGM 100:2008 Evaluation of measurement data-guide to the expression of uncertainty in measurement, International Organization for Standardization, Joint Committee for Guides in Metrology, France, 2008.

26. Spring, Technical Guide 2 A Guide on Measurement Uncertainty in Chemical \& Microbiological Analysis, Spring, Singapre, 2008.

27. ISO, ISO/IEC GUIDE 98-3:2008 Uncertainty of measurement-Part 3: guide to the expression of uncertainty in measurement (GUM:1995), International Organization for Standardization, Switzerland, 2008. 